Supplement of Nat. Hazards Earth Syst. Sci. Discuss., 2, 5171-5212, 2014

http://www.nat-hazards-earth-syst-sci-discuss.net/2/5171/2014/

doi:10.5194/nhessd-2-5171-2014-supplement

(C) Author(s) 2014. CC Attribution 3.0 License.

(c) (i)

Supplement of

\title{
Floods in the Niger basin - analysis and attribution
}

V. Aich et al.

Correspondence to: V. Aich (aich@pik-potsdam.de) 


\section{Supplementary material}
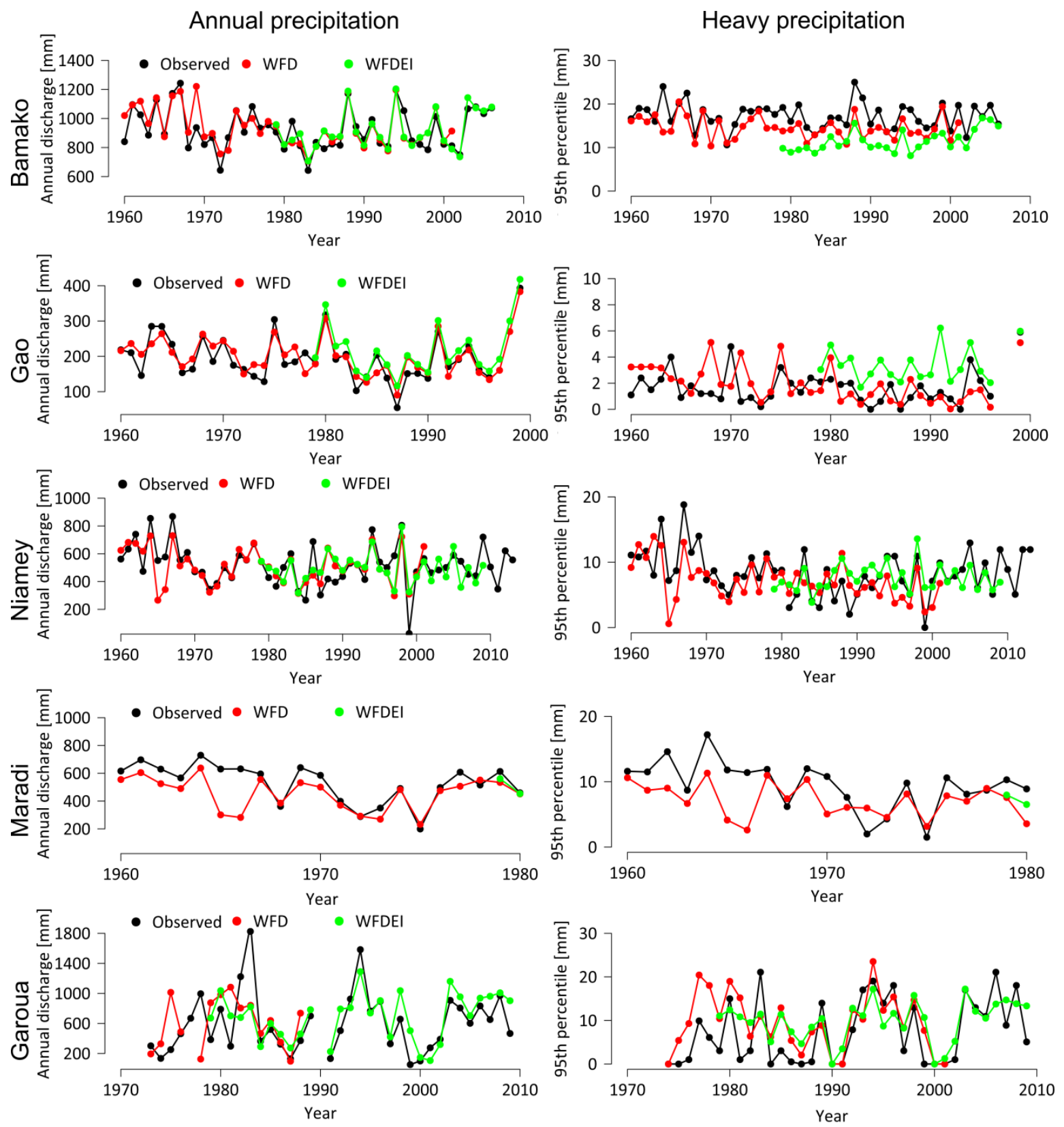

Figure S1 Validation of precipitation reanalysis data. Left: Annual sum of observed, WFD and WFDEI precipitation in Bamako and Gao (Mali). Right: $95^{\text {th }}$ percentile of daily precipitation for the year for observed, WFD and WFDEI precipitation in Bamako and Gao (Mali). 


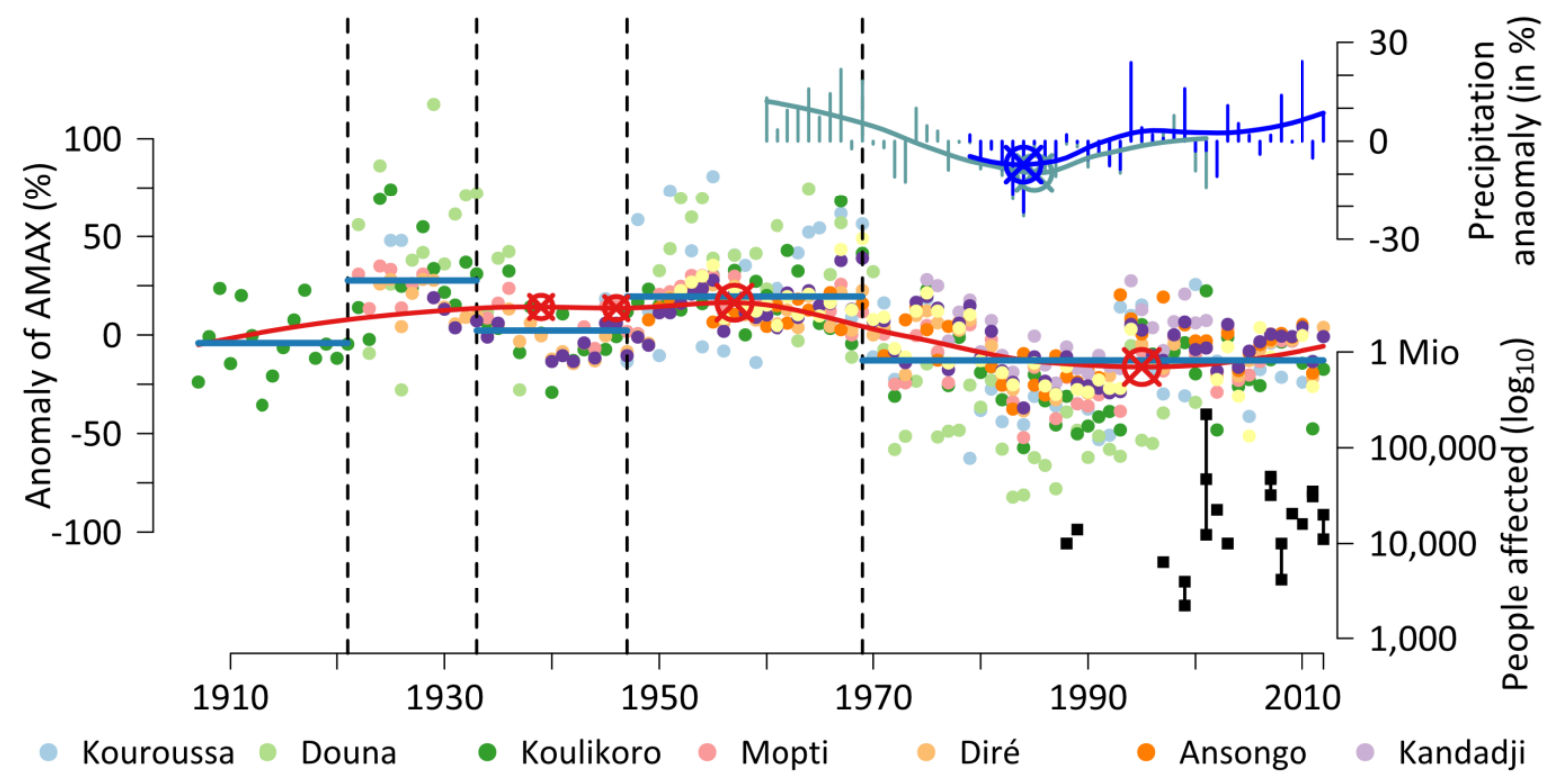

Figure S2 Decadal changes, trends and people affected by floods for all gauging stations affected primarily by the Guinean flood. 

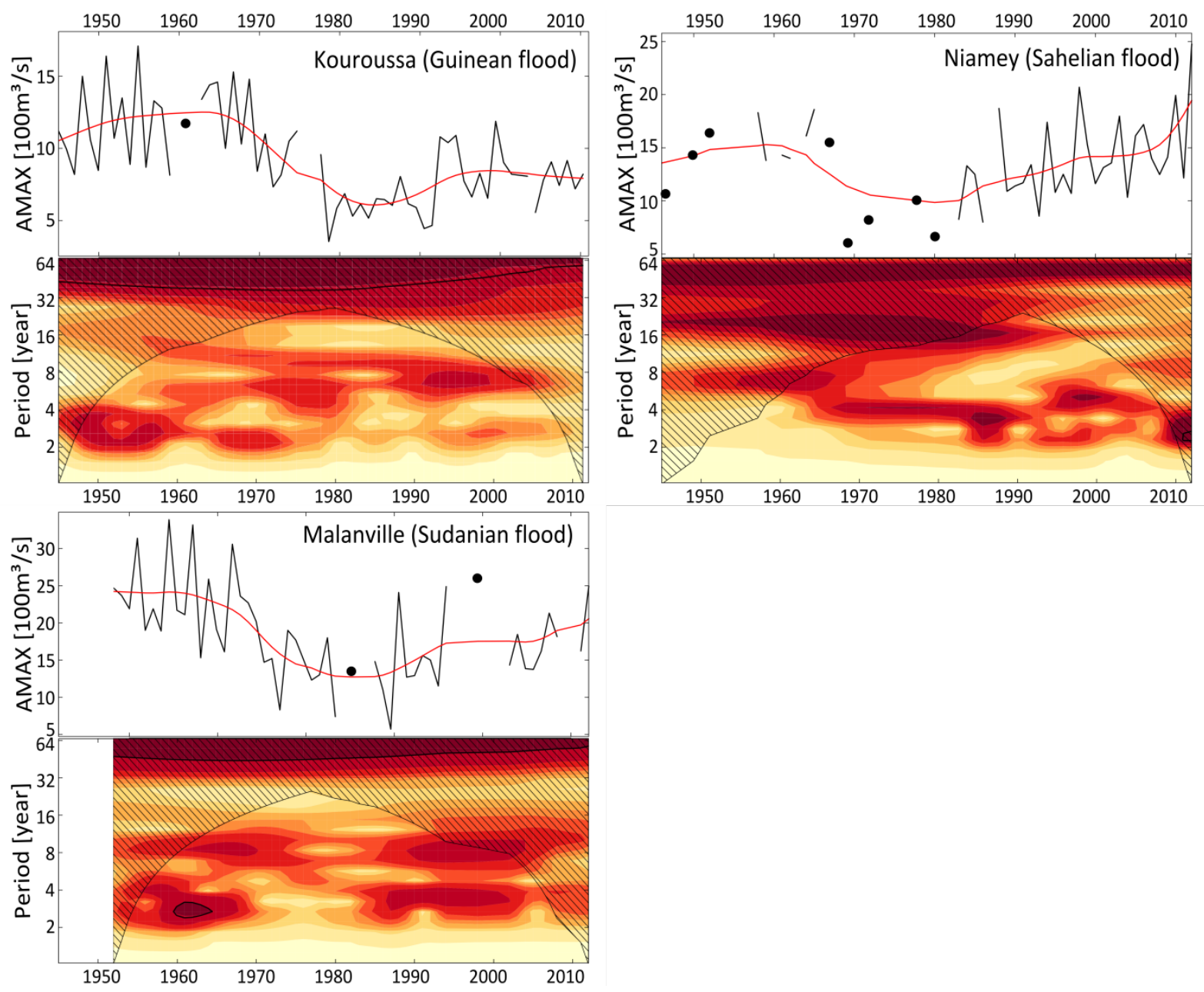

Figure S3 Top: AMAX time series with local regression curve in red. Bottom: wavelet power spectrum for Guinean, Sahelian, and Sudanian flooding. Brighter colors correspond to smaller wavelet coefficients and darker colors to higher coefficients with the Morlet wavelet. The shaded area is outside the cone of influence and should not be included in the interpretation. 


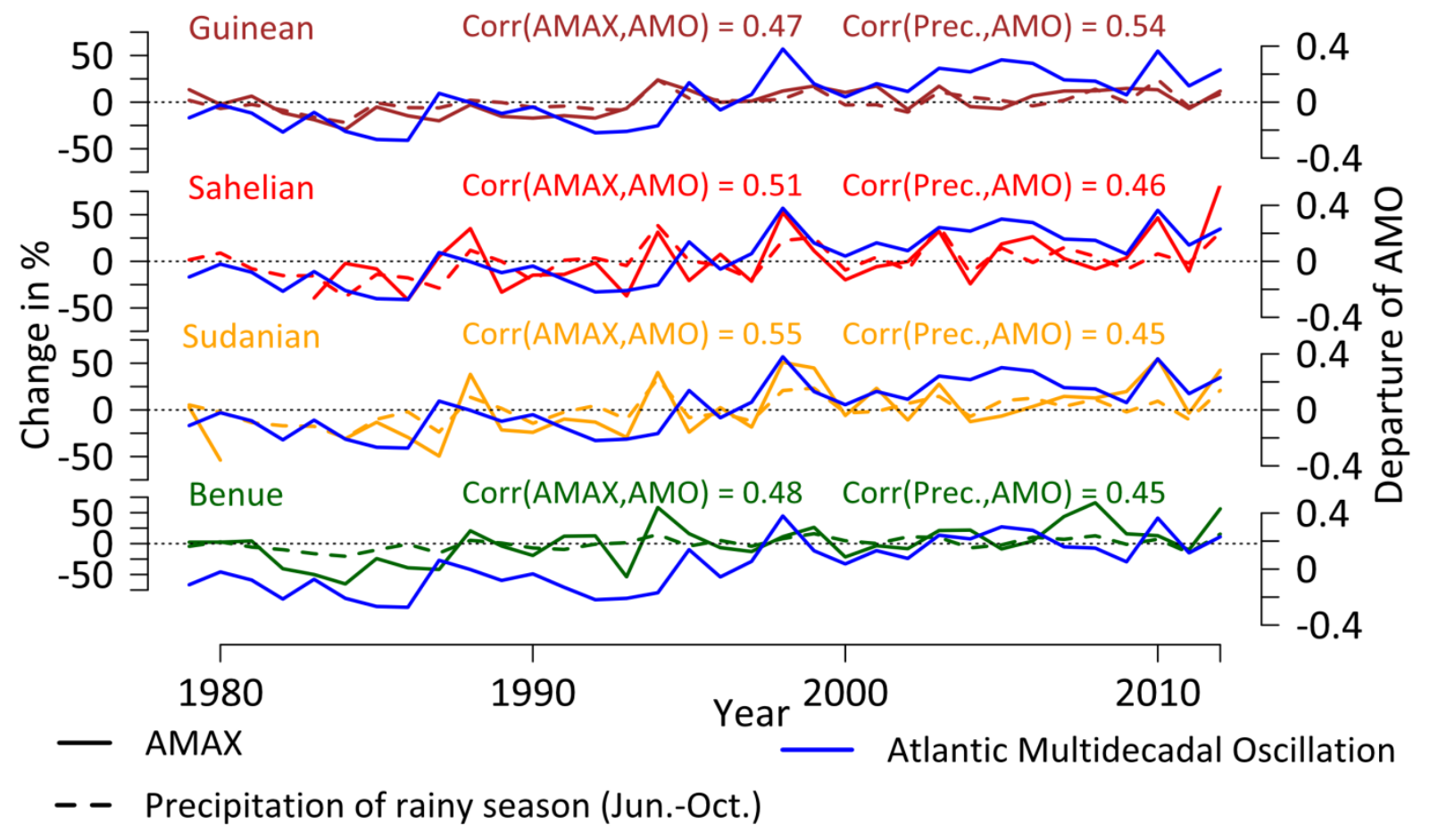

Figure S4 Correlation between Atlantic Multidecadal Oscillation and AMAX and annual precipitation for the four subregions of the Niger basin. 